\title{
AVALIAÇÃO DE UM PROJETO DE EXTENSÃO UNIVERSITÁRIA NA PERCEPÇÃO DE PROFESSORES DA EDUCAÇÃO BÁSICA
}

\author{
CONTRIBUTIONS OF A UNIVERSITY EXTENSION \\ PROJECT FOR TEACHERS OF THE BASIC EDUCATION
}

Resumo: Este estudo teve como objetivo analisar o alcance, a adoção e a eficácia do Projeto de Extensão Construindo um Futuro Saudável por meio da Promoção a Saúde (ProSaúde), da Universidade de Cruz Alta/RS. Participaram 12 professores de uma escola pública do município de Cruz Alta. Utilizou-se o modelo RE-AIM adaptado como instrumento. As informações foram interpretadas utilizando-se a análise de conteúdo. No ano de 2017, o ProSaúde alcançou $55 \%$ dos professores e a importância da temática saúde foi o principal motivo para a adesão ao projeto. Quanto à eficácia, foram apontadas: melhora nas estratégias de ensino, na relação aluno-professor, na adoção de hábitos saudáveis, no trabalho coletivo e na autonomia dos alunos. Conclui-se que a partir do projeto, professores e alunos aprenderam uns com os outros e os conhecimentos adquiridos foram levados para a casa dos alunos e professores, proporcionando uma mudança nos hábitos alimentares dos seus familiares.

Palavras chave: Extensão Universitária; Modelo de RE-AIM; ProSaúde.

\begin{abstract}
This study aimed to analyze the scope, adoption and effectiveness of the Extension Project Building a Healthy Future through Health Promotion (ProSaúde), from the University of Cruz Alta/RS. Twelve teachers from a public school in the municipality of Cruz Alta took part in it. The RE-AIM model adapted as an instrument was used and the information was interpreted using content analysis. In 2017, ProSaúde reached $55 \%$ of the teachers and the importance of health issues was their main reason for joining the project. Regarding efficacy, they pointed out: improvement in teaching strategies, student-teacher relationship, adoption of healthy habits, collective work and student autonomy. The results led to the conclusion that from their participation in the project, teachers and students learned from each other and the knowledge acquired was taken home by them, providing a change in their relatives' eating habits.
\end{abstract}

Keywords: University Extension; RE-AIM Model; ProSaúde. 


\section{Introdução}

A Lei de Diretrizes e Bases da Educação Nacional $\mathrm{n}^{\circ}$ 9.394/96, modificada pela Lei $\mathrm{n}^{\circ}$ 12.061, de 2009 , ressalta que a partir dos 4 anos e até os 17 anos de idade, o estado tem a obrigação de oferecer aos cidadãos educação básica, iniciando pela préescola, posteriormente ensino fundamental e por fim ensino médio. A Lei também salienta que, além dos conteúdos curriculares, os professores da educação básica devem trabalhar com os alunos os temas transversais (BRASIL, 2009). Os temas transversais caracterizam-se por um conjunto de assuntos que aparecem transversalizados em áreas determinadas do currículo, que se constituem na necessidade de um trabalho mais significativo e expressivo de temáticas sociais na escola. Os Parâmetros Curriculares Nacionais - PCNs (BRASIL, 1998) trazem como sugestão de temáticas transversais a ética, a saúde, o meio ambiente, a orientação sexual e a pluralidade cultural.

Com relação ao tema saúde, é importante destacar que, por ser um tema amplo, falado e debatido por muitas pessoas de diferentes níveis de escolaridade e realidades sociais, a saúde se torna bastante difícil de conceituar. O conceito de saúde mais difundido, não só no senso comum, mas também afirmado por grande parte da comunidade médica e científica, suscita seu entendimento de que a saúde é a ausência de doença (BATISTELLA, 2007). Por outro lado, a Organização Mundial da Saúde (OMS), em seu documento de criação em 1948, define a saúde como "um completo estado de bem-estar físico, mental e social, e não apenas a ausência de doença ou enfermidade". Mesmo esta definição da OMS também sofre algumas críticas mais modernas, pois o "completo estado de bem-estar" pode ser difícil de ser alcançado, gerando frustrações que distanciam cada vez mais o indivíduo de um estado considerado saudável. Desta forma, alguns autores propõem que a saúde deva ser pensada como a capacidade de enfrentar os erros e não a falta desses erros (BATISTELLA, 2007).

Embora os avanços ocorridos no último século sejam inegáveis e importantes no que se refere à assistência e à recuperação da saúde, o que se tem discutido, principalmente nas duas últimas décadas, é que se faz necessária a implementação de outras estratégias para se conquistar uma melhor condição de saúde e de qualidade de vida, visando não somente a recuperação e proteção, mas principalmente a promoção da saúde.

O movimento de promoção de saúde vem ganhando força, com a realização de uma série de conferências internacionais que reforçam suas práticas. Em 1986, na primeira Conferência Internacional sobre Promoção de Saúde, foi publicada a Carta de Ottawa, que ampliou o significado da concepção de promoção de saúde de um conjunto de ações voltadas para a prevenção das doenças e riscos individuais, para uma visão que considerava a influência dos aspectos sociais, econômicos, políticos e culturais sobre as condições de vida e saúde. Assim, a saúde passou a ser compreendida enquanto qualidade de vida e não apenas como ausência de doença, determinando que os problemas de saúde sejam enfrentados valendo-se de ações intersetoriais, visto que extrapolam a responsabilidade exclusiva do setor saúde (WORLD HEALTH ORGANIZATION - WHO, 1986).

Dessa maneira, a promoção da saúde passou a ser vista como uma estratégia mediadora entre pessoas e ambiente, visando aumentar a participação dos sujeitos e da coletividade na modificação dos determinantes do processo saúde doença, como emprego, renda, educação, cultura, lazer e hábitos de vida, devendo proporcionar aos povos meios necessários para melhorar sua saúde, cabendo ao estado a responsabilidade de reduzir as diferenças, assegurar a igualdade de oportunidades e promover os meios que permitam a todos desenvolver um melhor controle sobre ela.

Para isso, a Política Nacional de Promoção da Saúde (BRASIL, 2014) recomenda a elaboração intersetorial de estratégias de modo participativo e inclusivo, conformando redes de corresponsabilidades para possibilitar a integralidade das práticas em saúde. Assim, a promoção da saúde deve ser assumida como responsabilidade de todos os setores e exige o comprometimento de toda a sociedade, numa ação coordenada de todos os implicados: governo, organizações não governamentais, meios de comunicação e população (BUSS; CARVALHO, 2009).

Acreditamos que a promoção de saúde, vista desta forma, representa uma possibilidade de mudança radical no modo atual de conceber e praticar saúde. Mas, para chegar lá, será preciso revisitar criticamente seus fundamentos e práticas. Nesta perspectiva, compactuamos com Bressam e Medeiros (2014) quando apontam para a importância da educação como uma estratégia de fortalecimento da participação social a partir do empoderamento, entendido como a prática de compartilhar poder de decisão, a construção de saberes e práticas e formas de participação. Nesse cenário, a escola tem representado um importante local, abrigando amplas possibilidades de iniciativas para o desenvolvimento de atividades de promoção da saúde (CASEMIRO; FONSECA; SECCO, 2014).

Nesse sentido, enfocamos, em nosso estudo, a promoção da saúde no ambiente escolar, que também pode ser entendida como "educação em saúde". A educação em saúde é compreendida como qualquer combinação intencional de experiências de aprendizagem com objetivo de facilitar medidas comportamentais ou ações sobre os determinantes sociais da saúde a serem adotadas por pessoas, ou comunidades (ASSIS et al., 2010). É ainda percebida como a expressão do processo teórico-prático planejado e embasada a fim de se obterem os resultados desejados, que visa integrar vários saberes, sejam científicos, populares ou do senso comum, proporcionando aos envolvidos a percepção crítica e a 
participação responsável e autônoma (DINIZ; FIGUEIREDO; SCHALL, 2009), devendo favorecer uma ação mais reflexiva e crítica sobre o conceito de saúde, com investigações de demandas e temas pertinentes à comunidade escolar e, particularmente, aos escolares.

Uma das formas de se trabalhar com a temática saúde na escola é a partir da metodologia de projetos. Está metodologia "baseia-se na relação vida/escola, defendendo os princípios de autonomia, liberdade, igualdade e democracia e buscando, sobretudo, processos de mudança e emancipação social" (OLIVEIRA; TINOCO; SANTOS, 2014, p.12), e a escola passa a ser uma escola aberta, contribuindo para o crescimento do homem e da sociedade (OLIVEIRA; TINOCO; SANTOS, 2014).

Os projetos mais desenvolvidos na escola são os de pesquisa, de produto, de ensino, de intervenção e de aprendizagem. Nos projetos de aprendizagem, em especial, o aluno passa a ser um aluno pesquisador e o professor o seu orientador. O desenvolvimento dos projetos de aprendizagem ocorre a partir de quatro pilares: a) a liberdade de escolha do tema do projeto por parte dos alunos (em conversa com o professor); b) a formação de pequenas turmas de estudantes para desenvolver o projeto (trabalho em equipe); c) a visão de um laboratório sem fronteiras (utilizando diversificados recursos); e, d) o compartilhamento dos resultados obtidos no projeto (MOURA; BARBOSA; MOREIRA, 2010).

Destaca-se que esta metodologia de ensino, embora não seja recente, ainda é pouco usada pelos professores da rede básica de ensino e, desta forma, tanto as universidades quanto entidades que buscam contribuir com a sociedade podem ajudar no desenvolvimento desses projetos nas escolas, a partir da extensão universitária. É neste contexto de que a universidade e a escola podem e devem trabalhar juntas os temas e problemas sociais que o Curso de Educação Física da Universidade de Cruz Alta (UNICRUZ), a partir do Grupo de Extensão e Pesquisa em Educação Física - GEPEF/UNICRUZ, levou para uma escola, localizada em um bairro de vulnerabilidade social do município de Cruz Alta/RS, o projeto de extensão "Construindo um Futuro Saudável por meio da Promoção a Saúde - ProSaúde". $\mathrm{O}$ referido projeto tem como objetivo refletir sobre as necessidades e demandas de saúde dos escolares e implementar metodologias participativas e práticas educativas, envolvendo a comunidade escolar na construção de projetos, a fim de melhorar as condições de saúde (KRUG, 2013).

O ProSaúde vem sendo renovado anualmente desde $2013^{1}$ e já teve como público-alvo alunos e professores de diferentes ciclos escolares. Em 2013, o projeto focou suas ações junto a dois professores e duas turmas de alunos do $3^{\circ}$ ano do ensino fundamental; em 2014 e 2015, as ações foram desenvolvidas junto à disciplina de Seminário Integrado, tendo como público-alvo uma turma de alunos do $2^{\circ}$ ano do ensino médio e seus respectivos professores, sendo que algumas ações foram direcionadas à comunidade escolar; em 2016, a equipe do projeto foi convidada pela escola para desenvolver suas ações junto aos professores dos anos iniciais do ensino fundamental, permanecendo esta parceria em 2017, tendo como objetivo colaborar com uma comunidade escolar (pais, alunos e professores) no planejamento e desenvolvimento de estratégias de promoção da saúde e prevenção de agravos, que permitam, entre outros, a melhoria do rendimento escolar, recuperação da autoestima e da autoconfiança e diminuição dos níveis de absenteísmo e repetência escolar (KRUG, 2017).

Desta forma e considerando que o ProSaúde já está instituído na escola, torna-se importante uma avaliação mais detalhada do projeto no sentido de conhecer melhor suas contribuições. Assim, justificase este estudo, que tem como objetivo analisar, na percepção de professores da educação básica, o alcance, a adoção e a eficácia do ProSaúde, da Universidade de Cruz Alta - RS.

\section{Material e Métodos}

Esse estudo caracteriza-se como um estudo de caso do tipo descritivo. Segundo Thomas e Nelson (2002), este tipo de estudo detalha uma única situação, com o objetivo de determinar dados singulares sobre o sujeito (ou instituição, comunidade, etc.) analisado, buscando compreender situações similares. É utilizado na pesquisa qualitativa e quantitativa, podendo ser de três tipos: descritivo, interpretativo ou avaliativo. O estudo de caso do tipo descritivo tem por finalidade observar, registrar e analisar os fenômenos sem entrar no mérito de seu conteúdo. Não há interferência do investigador na pesquisa descritiva, e este deve apenas procurar notar, com as devidas precauções, a intensidade e frequência com que o fenômeno acontece (THOMAS; NELSON; SILVERMAN, 2007).

Para a avaliação do ProSaúde, utilizou-se o modelo RE-AIM, que foi desenvolvido no fim da década de 1990, pelo pesquisador norte americano Dr. Russell Glasgow e sua equipe. O mesmo foi elaborado para auxiliar pesquisadores e gestores no planejamento e na avaliação de programas de saúde, buscando, desta forma, diminuir as lacunas entre a pesquisa e a prática e maximizar o impacto das intervenções na saúde pública (GLASGOW; VOGT, 1999). O RE-AIM foi traduzido e adaptado culturalmente para a realidade brasileira por Almeida, Brito e Estabrooks (2013) e é constituído por cinco dimensões (Alcance, Adoção, Implementação, Eficácia e Manutenção).

No presente estudo, não iremos avaliar duas dimensões: a implementação e a manutenção. A implementação porque esta dimensão é avaliada pelos bolsistas do ProSaúde, assim como por informações documentais sobre o financiamento do projeto; e a 
manutenção porque se trata de uma escola e, durante o recesso escolar, professores e alunos não se fazem presentes na escola.

A dimensão alcance é individual e é definida pelo número absoluto, a proporção e a representatividade dos indivíduos comparada àqueles que desistem ou àqueles potencialmente elegíveis. A adoção é organizacional e é definida pelo número absoluto, a proporção e a representatividade das organizações e dos agentes de intervenção que estão dispostos a ingressar em um projeto. A eficácia é individual e define-se como o impacto de uma intervenção sobre desfechos importantes e potenciais efeitos positivos e negativos (ALMEIDA; BRITO; ESTABROOKS, 2013).

Para contemplar as informações necessárias para a análise das dimensões alcance, adoção e eficácia, utilizou-se uma ficha diagnóstica com questões fechadas e abertas, relacionadas aos dados sociodemográficos (idade e sexo); informações profissionais e questões referentes ao projeto (atividades desenvolvidas, motivo de ingresso no projeto, aprendizagens proporcionadas e adversidades). A referida ficha foi respondida por 12 professores da escola, tendo como critério ter participado do projeto em algum momento desde o ano de 2013 até setembro do ano de 2017. Para completar a análise da dimensão alcance, ainda, buscaram-se informações nos relatórios do ProSaúde e nos registros da escola.

O Quadro 1 resume as informações, fontes ou instrumentos e participantes do estudo, de acordo com as dimensões do RE-AIM.

\begin{tabular}{|c|c|c|c|c|}
\hline Dimensões & Informações & $\begin{array}{c}\text { Fontes ou } \\
\text { instrumentos }\end{array}$ & \multicolumn{2}{|c|}{ Participantes do estudo } \\
\hline \multirow{4}{*}{ Alcance } & Número total de & Documental & Registros da escola & \multirow{6}{*}{ NO } \\
\hline & $\begin{array}{l}\text { Número de professores } \\
\text { participantes }\end{array}$ & Documental & $\begin{array}{l}\text { Relatórios do } \\
\text { ProSaúde }\end{array}$ & \\
\hline & $\begin{array}{l}\text { Características } \\
\text { sócio-demográficas }\end{array}$ & Ficha diagnóstica & Professores & \\
\hline & $\begin{array}{l}\text { Nível de instrução dos } \\
\text { professores }\end{array}$ & Ficha diagnóstica & Professores & \\
\hline \multirow[b]{2}{*}{ Adoção } & Motivos de ingresso & Ficha diagnóstica & Professores & \\
\hline & $\begin{array}{l}\text { Forma de conhecimento } \\
\text { do Projeto }\end{array}$ & Ficha diagnóstica & Professores & \\
\hline \multirow{3}{*}{ Eficácia } & Projetos desenvolvidos & Ficha diagnóstica & Professores & \multirow{3}{*}{ NI } \\
\hline & $\begin{array}{l}\text { Beneficios e } \\
\text { aprendizagens } \\
\text { proporcionadas }\end{array}$ & Ficha diagnóstica & Professores & \\
\hline & Fatores adversos & Ficha diagnóstica & Professores & \\
\hline
\end{tabular}

$\mathrm{NO}=$ nível organizacional e $\mathrm{NI}=$ nível individual

Fonte: Elaborado pelas autoras

Todos os participantes do estudo assinaram o Termo de Consentimento Livre e Esclarecido e o projeto foi aprovado pelo Comitê de Ética em Pesquisa da Universidade de Cruz Alta/RS, sob Parecer $\mathrm{n}^{\circ}$. 1.589 .605

Os dados foram interpretados a partir da análise de conteúdo, considerando suas três etapas: a préanálise, em que se realizou a organização e seleção do material, para a construção dos indicadores; a exploração do material, em que foi realizada a leitura do material, codificação e escolha das categorias; e, a análise, em que ocorreu a descrição e a análise dos dados. O tipo de análise de conteúdo utilizada foi de exploração quantitativa, em que foi realizada a exploração das temáticas, buscando informações emergentes, sendo essas interpretadas baseadas em quantidades de referências e na frequência das ocorrências (BARDIN, 2011).

\section{Resultados e Discussão}

A dimensão alcance foi avaliada considerando o número total de professores da escola (36) em relação ao número de professores que participaram do projeto em algum momento em cada ano (2013 a 2017) de sua renovação. Estas informações foram obtidas a partir dos registros da escola e dos relatórios parciais e finais dos bolsistas e coordenadora do ProSaúde. Os resultados apontaram para um aumento crescente de professores à medida que o mesmo permanecia na escola. Ou seja, do total de 36 professores, participaram do projeto: em 2013, 2 (5\%) professores; em 2014, 6 (17\%); em 2015, 9 (27\%); em 2016, 17 (47\%); e, em 2017, 20 (55\%) professores.

Embora o alcance em 2017 tenha sido significativo, essa porcentagem poderia ser maior, visto que novas e diversificadas estratégias de ensino contribuem significativamente na aprendizagem dos estudantes. Notou-se uma resistência por partes dos professores em mudar hábitos antigos, como trabalhar de forma interdisciplinar com métodos variados. Para se trabalhar de forma interdisciplinar, é necessário planejar junto, porém, atualmente, a gestão escolar não prevê tempo e espaço para os professores fazerem este planejamento em equipe.

Fortunato, Confortin e Silva (2013) reforçam este posicionamento, salientando que, para ocorrer uma interdisciplinaridade, é necessário um diálogo entre os alunos, professores e gestores, necessitando:

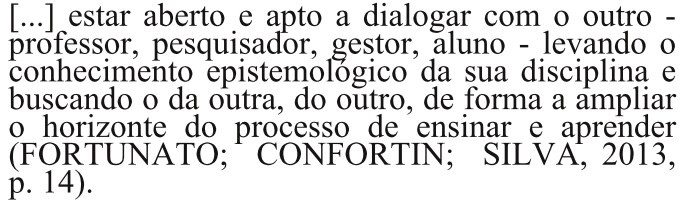

Para que o docente atue numa nova proposta, ele tem que acreditar, ter valores e atitudes, desenvolvendo o senso crítico dos estudantes; do contrário, estará desenvolvendo a prática tradicional e a inovação acaba sendo "só fachada" (CHIRELLI; MISHIMA, 2004).

Oliveira, Tinoco e Santos (2014) reforçam que:

A prática escolar está centrada basicamente na sequenciacão de conteúdos curriculares segmentados em disciplinas. Em razão disso, muitos professores se sentem inseguros em romper com essa tradicão e buscar formas alternativas para seu trabalho pedagógico (p. 15).

Dos professores participantes do ProSaúde, retornaram com a ficha diagnóstica somente 12 , sendo 
todas do sexo feminino, com idade média de 43 anos. Assim, 11 (92\%) professoras tinham formação na área das Ciências Humanas e Sociais e apenas 1 (8\%) com formação em Magistério; $6(50 \%)$ professoras se formaram na década de $2000,2(17 \%)$ na década de 2010, $1(8 \%)$ na década de 1990 e $3(25 \%)$ na década $1980 ; 8(67 \%)$ professoras realizaram sua formação inicial na Universidade de Cruz Alta (UNICRUZ), 2 $(17 \%)$ na Universidade Norte do Paraná (UNOPAR), 1 (8\%) na Universidade Regional do Noroeste do Estado do Rio Grande do Sul (UNIJUI) e $1(8 \%)$ na Escola Estadual de Ensino Médio Professor Annes Dias.

A partir destes resultados, observa-se que 8 (92\%) professoras apresentavam formação superior, adquirida na década de 2000 (50\%), tendo entre 7 e 25 anos de carreira, o que Huberman (2000) classifica como fase da experimentação ou diversificação na profissão docente. Neste período, encontram-se três padrões de professores: a) os que se desafiam, tornamse mais dinâmicos, com metodologias e modos de avaliação diversificados; b) os que se envolvem mais com o sistema administrativo, visando promover-se profissionalmente; e, c) os que reduzem seus compromissos com a docência, podendo abandoná-la ou exercer outra profissão paralela. A partir das observações realizadas, pode-se afirmar que as professoras envolvidas no projeto se encontravam no primeiro padrão, pois continuavam lecionando e diversificando suas estratégias de ensino.

Com relação ao questionamento de como as professoras tiveram conhecimento do ProSaúde, 7 (58\%) relataram que foi por meio da coordenação do projeto e $5(42 \%)$ por meio da supervisão da escola. Dentre os motivos que as levaram participar do ProSaúde, $8(67 \%)$ responderam que foi pela importância da temática saúde no cotidiano escolar e as demais respostas que emergiram foram: por ser uma metodologia diferente de ensino, facilitando o desenvolvimento das disciplinas, abrindo para novos conhecimentos e pelo tempo e espaço para um planejamento comum entre os professores.

A importância da temática saúde no cotidiano escolar, assim como outros temas transversais, é enfatizada pelos Parâmetros Curriculares Nacionais PCNs, que apontam para a necessidade de trabalhar tais temas integrando o currículo escolar de forma transversal, ampla, constante, sistemática, integrada e não como áreas ou disciplinas (BRASIL, 1998). Neste sentido, as professoras encontraram no ProSaúde uma forma de desenvolver tais temáticas. Gomes (2012) reforça que:

$$
\begin{aligned}
& \text { A escola pode e deve trabalhar a saúde como } \\
& \text { parte integrante da vida das pessoas, considerando } \\
& \text { as experiências e o saber da comunidade escolar, } \\
& \text { de modo a favorecer nesse espaço uma ação mais } \\
& \text { reflexiva e crítica, onde a saúde possa ser pensada } \\
& \text { enquanto tema de ensino/aprendizagem para a } \\
& \text { produção do conhecimento (p. 15). }
\end{aligned}
$$

Gomes (2012) também enfatiza que a temática saúde na escola deve ser trabalhada de modo participativo, construído coletivamente, a partir do empoderamento e da autonomia dos sujeitos e da comunidade, na busca de transformações significativas na comunidade escolar. Venturi, Pedroso e Mohr (2013) destacam a importância do professor estar preparado para desenvolver a educação em saúde com os estudantes, abordando novas metodologias de ensino, para que haja construção de conhecimento e mudanças comportamentais e atitudinais por partes dos estudantes.

A dimensão eficácia foi analisada a partir dos indicadores: projetos de aprendizagem desenvolvidos, benefícios e aprendizagens proporcionados e fatores adversos. Em 2013, foi desenvolvido junto a duas turmas de terceiro ano do ensino fundamental o projeto de aprendizagem "Matando piolho", para assim abordar o tema higiene, apontado pelas professoras com um dos principais problemas de saúde dos alunos. Em 2014 e 2015, foi desenvolvido por alunos do ensino médio e seus respectivos professores o projeto "Câncer: alerta de prevenção". Este tema foi escolhido pelos alunos em virtude de que a maioria estava vivenciando esta doença entre seus familiares. Em 2016, foi desenvolvido o projeto "Meio ambiente: cuidando da higiene e da saúde", tema proposto pelas professoras dos anos iniciais do ensino fundamental, tendo a participação de 12 turmas de alunos e suas respectivas professoras. Em 2017, foram desenvolvidos dois projetos: "Horta Solidária" e "Bandarra em ação", que envolveram as 14 turmas do ensino fundamental do turno da tarde.

Em relação às ações propostas para o desenvolvimento dos projetos, as mais citadas pelas professoras foram as palestras, abordando os temas câncer, higiene, alimentação saudável, violência contra a mulher, piolho, cuidado com os animais, autoestima e conviver com a diferença. Além das palestras, as professoras também apontaram as rodas de conversas e as leituras de textos. De acordo com Nunes e Silva (2011), a extensão universitária aplicada na escola tem o papel de desenvolver ações (palestras, seminários, etc.) sobre temas polêmicos da sociedade onde a escola está inserida. Entretanto, destaca-se que as ações devem ir além de palestras, e os professores devem adotar diferentes metodologias docentes, possibilitando-se a experimentação do novo, a partir de experiências profissionais (WENGZYNSKI; TOZETTO, 2012).

Neste sentido, aponta-se para os projetos de aprendizagem, pois, segundo Schlemmer (2001), esta metodologia de ensino possibilita aos alunos e professores optarem pelo tema a ser investigado, frente às dúvidas, conflitos, curiosidades e situações encontradas nos seus cotidianos, ou seja, as decisões são tomadas de forma heterárquica, e não prescrita pelo professor. O referido autor também salienta que a metodologia de projetos de aprendizagem oportuniza a cooperação entre os estudantes e professores, o desenvolvimento da autonomia, comunicação e senso crítico dos alunos. De acordo com Santos (2012, p. 159), "por meio de projetos os elementos curriculares adquirirão novas formas e os conteúdos não serão 
memorizados, mas apreendidos compreensivamente".

Destaca-se que os conteúdos dos projetos de aprendizagem devem ser trabalhados de uma forma flexível, para o aluno ter a liberdade de elaborar suas questões investigativas, levando seus interesses pessoais para dentro da escola. Desta forma, será possível deparar-se com um sujeito empenhado com a sua aprendizagem, a fim de buscar diversas formas de solucionar os problemas elaborados por ele mesmo (MATTOS; FERRARI JÚNIOR; MATTOS, 2005).

Todas as professoras destacaram que ter participado do ProSaúde trouxe benefícios para sua vida pessoal e profissional, sendo o principal deles o aprender a trabalhar com projetos temáticos, ampliando suas estratégias de ensino. De acordo com as professoras, esta metodologia de ensino permitiu ensinar e aprender ao mesmo tempo. Ainda de acordo com as professoras, o ProSaúde contribuiu, também, para a mudança de seus hábitos alimentares, bem como dos seus alunos. Outros benefícios e aprendizagens foram apontados pelas professoras, tais como: relação professor/aluno e aluno/aluno, ou seja, de acordo com $10(84 \%)$ professoras, a participação no projeto aumentou o envolvimento e a integração dos alunos com os colegas, professores e a comunidade, fortalecendo as ações de promoção da saúde e o trabalho coletivo.

A mudança de atitude dos alunos também foi citada por $10(84 \%)$ professoras. Segundo as mesmas, ocorreram mudanças significativas, tais como: maior consciência ambiental; entusiasmo, disposição e autonomia ao realizar as tarefas; maior cuidado com a sala de aula; melhor compreensão sobre doenças e acompanhamento médico; e, as aprendizagens adquiridas na escola passaram a ser desenvolvidas nas casas dos alunos.

No que concerne à relação dos alunos com a comunidade, Bezerra et al. (2010) relatam que:

\section{[...] é imprescindível que ocorra integração entre a escola e a comunidade atendida, com reconhecimento e valoração dos saberes extracurriculares e efetivação de parcerias no trabalho educativo, atingindo o maior contingente de pessoas em sua área de localização. Devemos considerar que todos os participantes do processo educativo têm a capacidade de elaboração de propostas para a melhoria da educação (BEZERRA et al., 2010, p. 282).}

Ressalta-se que um dos projetos mais comentados pelas professoras foi a "Horta Solidária", idealizado por uma professora estagiária dos anos inicias do Ensino Fundamental, denominado assim porque tinha como principal objetivo distribuir mudas de hortaliças junto à comunidade local. Este projeto foi desenvolvido no ano de 2017 por todas as professoras dos anos iniciais do Ensino Fundamental, segundo as quais, a partir deste projeto, os alunos melhoraram suas atitudes; a consciência ambiental; o encorajamento e a autonomia ao realizar tarefas; a adoção de uma alimentação saudável; e, uma melhor compreensão sobre alimentação, doenças e acompanhamento médico. Canal (2011) ressalta que o professor deve incentivar a adoção de bons hábitos alimentares, conscientizando a si próprio e aos que estão ao seu redor sobre uma melhor qualidade de vida a partir de uma alimentação saudável.

A horta em ambiente escolar é um dos métodos de diversificar o padrão alimentar tanto dos alunos como dos pais e da comunidade na qual a escola está inserida (MORGADO, 2006). Cribb (2010) reforça este posicionamento salientando que a mesma propicia compreensão da necessidade da preservação do meio ambiente escolar, desenvolve a criatividade, cooperação, respeito, responsabilidade e autonomia, resultados que também foram observados no presente estudo.

Sobre os fatores adversos, 7 (58\%) professoras apontaram para a necessidade de: mais tempo para o professor se envolver no projeto; ampliação do número de encontros e atividades com os professores, bem como o envolvimento de mais professores; a dificuldade de diálogo com os coordenadores do projeto; e, a necessidade de incluir todas as turmas da escola nas ações do projeto. Analisando estes resultados, notou-se que a maior parte está relacionada com a gestão escolar, como mais tempo para envolvimento dos professores no projeto. Silva, Cristino e Ivo (2008), enfatizam que, para um ensino de qualidade, todos os profissionais da escola, juntamente com a comunidade escolar, devem trabalhar juntos com os professores, pois o professor sozinho, sem apoio, dificilmente atingirá os objetivos da escola. Os autores ainda complementam que:

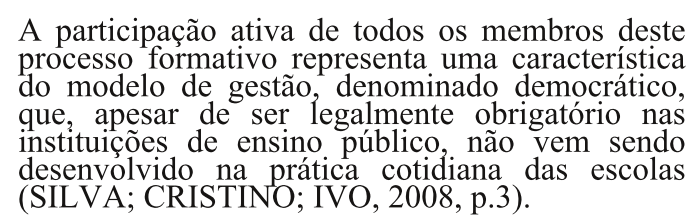

Uma gestão escolar próxima, com a participação de todos os envolvidos da escola, entenderá melhor as necessidades do professor, assim como o professor entenderá melhor a gestão educacional, encontrando alternativas para se trabalhar em equipe de forma que ninguém fique sobrecarregado, desenvolvendo-se, portanto, um trabalho interdisciplinar, método necessário para um trabalho com projetos de aprendizagem. Talvez esse distanciamento entre docentes e gestão seja o motivo de as professoras salientarem o desejo de mais atividades com o grupo docente.

\section{Considerações Finais}

Os resultados do presente estudo permitem concluir que ter participado do ProSaúde proporcionou aos professores aprendizagens e contribuições, tanto no âmbito profissional como pessoal. A partir do projeto, as metodologias de ensino passaram a ser diversificadas, professores e alunos ficaram mais 
próximos e aprenderam uns com os outros, resultando em uma maior interação.

$\mathrm{Na}$ percepção das professoras, os alunos mostraram bastante entusiasmo durante as ações do projeto, passaram a ser mais autônomos, encorajados e a se preocupar mais com a própria sala de aula e meio ambiente. Os conhecimentos adquiridos com as ações do projeto foram estendidos para além dos muros da escola, ou seja, levados para as casas dos alunos e professores, proporcionando uma mudança nos hábitos alimentares, inclusive, de seus familiares. O projeto também oportunizou aos professores trabalharem outros tópicos de saúde, como o desenvolvimento da responsabilidade e o espírito coletivo dos alunos.

Constatou-se, também, que o projeto de extensão necessita de mais ações voltadas para os professores, isto é, mais atenção com os mesmos. Talvez esse seja um dos motivos da baixa taxa de participação e continuidade dos professores no projeto. Desta forma, a coordenação do ProSaúde poderia incluir, em um dos seus objetivos, temáticas voltadas especialmente à saúde integral dos professores, conseguindo, assim, melhor atender o público docente da educação básica.

\section{Referências}

ALMEIDA, F. A; BRITO, F. A.; ESTABROOKS, P. A. Modelo RE-AIM: traducão e adaptacão cultural para o Brasil. REFACS, Uberaba, v. 1, n. 1, p. 6-16, 2013.

ASSIS, S. S. et al. Educação em saúde - proposta de utilização de um modelo no ensino de ciências. REMPEC Ensino, Saúde e Ambiente, São Paulo, v.3, n. 2 p.108-120, Ago. 2010.

BARDIN, L. Análise de conteúdo. 2 ed. São Paulo: Edições 70, 2011.

BATISTELLA, C. Abordagens Contemporâneas do Conceito de Saúde. In: FONSECA, A. F. (Org.). O território e o processo saúde-doença. Rio de Janeiro: Editora Fiocruz, 2007. p. 51-86.

BEZERRA, Z. F. et al. Comunidade e escola: reflexões sobre uma integracão necessária. Educar em Revista Curitiba, n. 37, p. 279-291, 2010.

BRASIL. Ministério de Educação e do Desporto. Parâmetros Curriculares Nacionais: terceiro e quarto ciclos: Educação Física. Brasília, 1998. Disponível em: $<$ http://portal.mec.gov.br/seb/arquivos/pdf/ciencias.pdf $>$. Acesso em: 10 maio 2017.

Lei $N^{\circ}$ 9.394, de 20 de dezembro de 1996. Diretrizes e Bases da Educação Nacional. Brasília, DF, 20 dez. 2009. Disponível em:

$<$ http://www.planalto.gov.br/ccivil_03/Leis/L9394.htm>. Acesso em: 01 jul. 2017.

Ministério da Saúde. Política Nacional de Promoção da Saúde - PNPS. Brasília, 2014. Disponível em: <http://www.blog.saude.gov.br/570-perguntas-erespostas/34641-ministerio-lanca-politica-nacional-depromocao-da-saude.html>. Acesso em: 25 jul. 2018.
BRESSAN, A.; MEDEIROS, D. C. A. Promoção da saúde na escola. Revista Pátio, Porto Alegre, v. 1, n. 69. 2014.

BUSS, P. M.; CARVALHO, A. I. Desenvolvimento da promoção da saúde no Brasil nos últimos vinte anos (19882008). Ciência \& Saúde Coletiva, Rio de Janeiro, v. 14, n. 6, p. 2305-2316, 2009.

CANAL, V. A. P. Alimentação adequada dentro e fora do espaço escolar. 2001. 34 f. Monografia (Especialização em Ensino de Ciências) - Universidade Tecnológica Federal do Paraná, Medianeira, 2011.

CASEMIRO, J. P.; FONSECA, A. B. C. da; SECCO, F. V. M. Promover saúde na escola: reflexões a partir de uma revisão sobre saúde escolar na América Latina. Ciência \& Saúde Coletiva, Rio de Janeiro, v.19, n.3, p. 829-840, 2014.

CHIRELLI, M. Q.; MICHIMA, S. M. O processo ensinoaprendizagem crítico-reflexivo. Revista Brasileira de Enfermagem, Brasília, v. 3, n. 57, 2004

CRIBB, S. L. S. P. Contribuições da educação ambiental e horta escolar na promoção de melhorias ao ensino, à saúde e ao ambiente. Revista Eletrônica do Mestrado Profissional em Ensino de Ciências da Saúde e do Ambiente, São Paulo, v. 3, n. 1, p. 42-60, 2010.

DINIZ, M. C. P.; FIGUEIREDO, B. G.; SCHALL, V. T. Hortênsia de Hollanda: a arte da educacão em saúde para prevenção e controle das endemias no Brasil. História, Ciências, Saúde - Manguinhos, Rio de Janeiro, v. 16, n. 2, p. 533-556, 2009.

FORTUNATO, R.; CONFORTIN, R.; SILVA, R. T. Interdisciplinaridade nas escolas de educação básica: da retórica à efetiva ação pedagógica. Revista de Educação do Ideau, Getúlio Vargas, v. 8, n. 17, p. 1-15, 2013.

GLASGOW, T. M.; VOGT, S. M. B. Evaluating the public health impact of health promotion interventions: the REAIM framework. American Journal Public Health, v. 89, n. 9 , p. $1322-7,1999$.

GOMES, L. C. O desafio da intersetorialidade: a experiência do Programa Saúde na Escola (PSE) em Manguinhos, no município do Rio de Janeiro. 2012. $185 \mathrm{f}$. Dissertação (Mestrado em Ciências na área de Saúde Pública) - Escola Nacional de Saúde Pública Sérgio Arouca, Rio de Janeiro, 2012.

HUBERMAN, M. O ciclo de vida professional de professores. In: NÓVOA, A. (Org.). Vida de professores. Porto: Porto Editora, 2000.

KRUG, M. R. Construindo um futuro saudável por meio da promoção à saúde. Projeto de Extensão. Pro-Reitoria de Pós-Graduacão, Pesquisa e Extensão da Universidade de Cruz Alta, Cruz Alta, 2013.

M. R. Aprendizagem por Projetos na Educação

Básica: A Educação Física como Disciplina Articuladora. Projeto de Extensão. Pro-Reitoria de Pos-Graduação, Pesquisa e Extensão da Universidade de Cruz Alta, Cruz Alta, 2017.

MATTOS, E. B. V.; FERRARI JUNIOR, J. C.; MATTOS, M. V. P. Projetos de Aprendizagem e o Uso de

TIC's-Tecnologias de Informação e Comunicação: Novos Possíveis na Escola. RENOTE, Porto Alegre, v. 3, n. 2, p. $1-11,2005$

MORGADO, F. S. A horta escolar na educação ambiental e alimentar: experiência do Projeto Horta Viva nas escolas municipais de Florianópolis. 2006. Trabalho de Conclusão do Curso (Graduação) - Faculdade de Agronomia, Universidade Federal de Santa Catarina. Florianópolis, 2006.

MOURA, D G. BARBOSA, E. F ; MOREIRA, A. F O Aluno Pesquisador. In: ENCONTRO NACIONAL DE DIDATICA E PRÄTICAS DE ENSINO, 15., Belo Horizonte, 2010. Anais eletrônicos... Recife, Tecnologia de Projetos, 2010. Disponível em:

$<$ http://www.tecnologiadeprojetos.com.br/banco objetos/\% 
7BFD0F0B4F-7178-443E-

BEA147C03C68BA62\%7D O\%20Aluno $\% 20$ Pesquisador $\%$ $20 \% 20$ texto $\% 20$ para $\% 20 X \bar{V} \% 20$ ENDIPE $\% 202010 \% 20 \% 2$ 0D\%C3\%A1 cio \%20et \%20al\%20pdf.pdf>. Acesso em: 30 jan. 2018.

NUNES, A. L. P. F.; SILVA, M. B. C. A extensão universitária no ensino superior e a sociedade. Mal-Estar e Sociedade, Barbacena, v. 4, n. 7, p. 119-133, 2011.

OLIVEIRA, M.S.; TINOCO, G. A.; SANTOS, I. B. A. Projetos de letramento e formação de professores de língua materna. 2. ed. Natal: EDUFRN, 2014.

SANTOS, M. P. Extensão universitária: espaço de aprendizagem profissional e suas relações com o ensino e a pesquisa na educação superior. Revista Conexão UEPG, Ponta Grossa, v. 8, n. 2, 154-163, 2012.

SCHLEMMER, E. Projetos de Aprendizagem Baseados em Problemas: uma metodologia interacionista/construtivista para formação de comunidades em Ambientes Virtuais de Aprendizagem. Colabor@ - Revista Digital da CVARICESU, Porto Alegre, v. 1, n. 2, 2001.

SILVA, F. R.; CRISTINO, A. P. R.; IVO, A. A. As concepções de gestão escolar de professores de educação física de uma escola pública do município de Santa Maria/RS. Educere et Educare - Revista de Educação, Cascavel, v. 3, n. 5, 2008.

THOMAS, J.R.; NELSON, J.K. Métodos de pesquisa em atividade física. 3. ed. Porto Alegre, Artmed Editora, 2002.
THOMAS, J. R.; NELSON, J. K.; SILVERMAN, S. J. Métodos de pesquisa em atividade física. 5. ed. Porto Alegre: Artmed, 2007.

VENTURI, T.; PEDROSO, I.; MOHR, A. Educação em saúde na escola a partir de uma perspectiva pedagógica: discussões acerca da formação de professores. In: ENCONTRO REGIONAL SUL DE ENSINO DE BIOLOGIA, 6., Santo Ângelo, 2013. Anais eletrônicos... Santo Angelo: URI, 2013. Disponível em:

$<\mathrm{http}$ ://santoangelo.uri.br/erebiosul2013/anais/?page $\mathrm{id}=25$ 7>. Acesso em: 30 jan. 2018.

WENGZYNSKI, C. D.; TOZETTO, S. S. A formação continuada de professores e as suas contribuiç̃es para aprendizagem da docência. In: SEMINARIO DE PESQUISA DO PROGRAMA DE PÓS-GRADUAÇÃO EM EDUCAÇÃO, 11., Maringá, 2012. Anais eletrổnicos... Maringá: Universidade Estadual de Maringá, 2012. Disponível em:

$<$ http://www.ppe.uem.br/publicacoes/seminario ppe 2012/t rabalhos/po/po_008.pdf $>$. Acesso em: 29 jan. 2018.

WORLD HEALTH ORGANIZATION - WHO. The Ottawa Charter for Health Promotion. Geneva, Switzerland. 1986. Disponível em:

$<$ http://www.who.int/healthpromotion/conferences/previous/ ottawa/en/index.html > . Acesso em: 24 jul. 2018.

\section{Notas}

${ }^{1}$ Programa Institucional de Bolsa de Extensão da Universidade de Cruz Alta - PIBEX/UNICRUZ (Editais: 2013-2014; 2014 - 2015 , 2015 - 2016 e 2017 - 2018). 